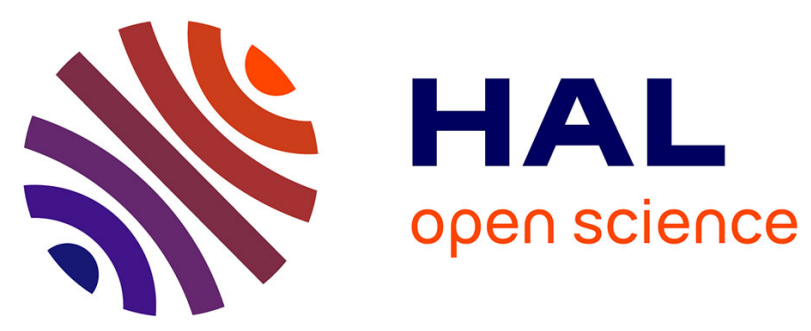

\title{
An attempt to quantify the impact of changes in wetland extent on methane emissions on the seasonal and interannual time scales
}

B. Ringeval, N. de Noblet-Ducoudre, P. Ciais, P. Bousquet, Christophe

Prigent, F. Papa, W. B. Rossow

\section{To cite this version:}

B. Ringeval, N. de Noblet-Ducoudre, P. Ciais, P. Bousquet, Christophe Prigent, et al.. An attempt to quantify the impact of changes in wetland extent on methane emissions on the seasonal and interannual time scales. Global Biogeochemical Cycles, 2010, 24 (2), pp.12. 10.1029/2008GB003354. hal00991319

\section{HAL Id: hal-00991319 \\ https://hal.science/hal-00991319}

Submitted on 17 Sep 2020

HAL is a multi-disciplinary open access archive for the deposit and dissemination of scientific research documents, whether they are published or not. The documents may come from teaching and research institutions in France or abroad, or from public or private research centers.
L'archive ouverte pluridisciplinaire HAL, est destinée au dépôt et à la diffusion de documents scientifiques de niveau recherche, publiés ou non, émanant des établissements d'enseignement et de recherche français ou étrangers, des laboratoires publics ou privés. 


\title{
An attempt to quantify the impact of changes in wetland extent on methane emissions on the seasonal and interannual time scales
}

\author{
Bruno Ringeval, ${ }^{1}$ Nathalie de Noblet-Ducoudré, ${ }^{1}$ Philippe Ciais, ${ }^{1}$ Philippe Bousquet, ${ }^{1}$ \\ Catherine Prigent, ${ }^{2}$ Fabrice Papa, ${ }^{3,4}$ and William B. Rossow ${ }^{3,4}$ \\ Received 29 August 2008; revised 23 October 2009; accepted 9 November 2009; published 17 April 2010.
}

[1] Climate variability impacts $\mathrm{CH}_{4}$ wetland sources as changes in flux density per unit area and via expansion or contraction of wetland areas in response to surface hydrological processes. This paper is a first attempt to isolate the role of varying wetland area on the seasonal and interannual variability of $\mathrm{CH}_{4}$ wetland emissions over the past decade.

Wetland area extent at monthly intervals was provided over the period 1993-2000 by a suite of satellite observations from multiple sensors. The regionally variable fraction of wetland area was optimized using satellite observations of flooded area as a first estimate and further adjusted to match the seasonal cycle of $\mathrm{CH}_{4}$ fluxes retrieved from a global atmospheric inversion. Wetland flux densities of $\mathrm{CH}_{4}$ were calculated by coupling the ORCHIDEE global vegetation model with a process-based wetland $\mathrm{CH}_{4}$ emission model, calibrated by optimizing its parameters at the site level against representative $\mathrm{CH}_{4}$ flux time series. For boreal bogs north of $50^{\circ} \mathrm{N}$, we found that variations in area contributed about $30 \%$ to the annual flux. For temperate and tropical wetlands, the variations in area has almost no influence on the annual $\mathrm{CH}_{4}$ emissions but contributes significantly to the seasonal behavior, accounting for $40 \%$ and $66 \%$ of the seasonal amplitude of fluxes, respectively. In contrast, the interannual variability of wetland area appears to be the dominant cause of interannual variations in regional $\mathrm{CH}_{4}$ emissions from wetlands at all latitudes (largest in the tropics), with up to $90 \%$ of annual flux anomalies explained by wetland area anomalies in some years. For example, in 1998, boreal wetlands north of $50^{\circ} \mathrm{N}$ contributed to approximately $80 \%$ of the positive anomaly according to our calculations. We also found that climate anomalies can lead to both increased emitting areas and decreased flux densities at the same time, with opposite effects on the total $\mathrm{CH}_{4}$ flux entering the atmosphere. With a view to forecasting the future trajectory of atmospheric methane content, our results point to the absolute necessity to be able to predict the variations in wetland extent, a hydrological problem, in order to affirm the reliability of simulations of changing methane emissions perturbed by climate.

Citation: Ringeval, B., N. de Noblet-Ducoudré, P. Ciais, P. Bousquet, C. Prigent, F. Papa, and W. B. Rossow (2010), An attempt to quantify the impact of changes in wetland extent on methane emissions on the seasonal and interannual time scales, Global Biogeochem. Cycles, 24, GB2003, doi:10.1029/2008GB003354.

\section{Introduction}

[2] Atmospheric methane $\left(\mathrm{CH}_{4}\right)$ plays a key role in climate both as a greenhouse gas and as a reduced compound

\footnotetext{
${ }^{1}$ Laboratoire des Sciences du Climat et de l'Environnement, Unité mixte CEA, UVSQ, CNRS, Gif-sur-Yvette, France.

${ }^{2}$ Laboratoire d'Etudes du Rayonnement et de la Matière en Astrophysique, Observatoire de Paris, CNRS, Paris, France.

${ }^{3}$ Cooperative Remote Sensing Science and Technology Center, NOAA, City College of New York, New York, New York, USA. USA.

${ }^{4}$ NASA Goddard Institute for Space Studies, New York, New York,

Copyright 2010 by the American Geophysical Union. 0886-6236/10/2008GB003354
}

controlling the global oxydizing capacity of the atmosphere [Houghton et al., 2001]. Its growth rate in the atmosphere decreased since the early 1990 s, but shows considerable interannual variation [Dlugokencky et al., 2001; Bousquet et al., 2006]. Natural wetland emissions are the largest single source in the global $\mathrm{CH}_{4}$ budget and also the most uncertain, ranging from 115 [Fung et al., 1991] up to $237 \mathrm{TgCH}_{4} / \mathrm{yr}$ [Hein et al., 1997], representing 20 to $40 \%$ of the global source. Wetland $\mathrm{CH}_{4}$ emissions seem to dominate the interannual variability of the global $\mathrm{CH}_{4}$ source [Walter et al., 2001b; Bousquet et al., 2006], and they are even suspected to be the main cause of the stalled $\mathrm{CH}_{4}$ growth rate since 1999 [Bousquet et al., 2006]. Wetland $\mathrm{CH}_{4}$ emissions arise from the combination of changes in the flux density 
and in the wetland area, both driven by changing weather and climate [Christensen et al., 2003]. For instance, temperature fluctuations will control the rates of methanogenesis and the length of the growing season in northern wetlands but also the area of wetlands through surface evaporation. Similarly, precipitation controls variations in $\mathrm{CH}_{4}$ flux density through changes in the water table depth, but also the regional wetland area. Finally, both temperature and rainfall determine Net Primary Productivity (NPP), which contributes to substrate availability for $\mathrm{CH}_{4}$ production under anaerobic conditions.

[3] In previous global modeling studies of $\mathrm{CH}_{4}$ emissions from wetlands, the variability of wetland area was calculated with simple assumptions. Walter et al. [2001b] assumed a fixed spatial distribution of wetlands [Matthews and Fung, 1987] and introduced seasonality by computing the water table depth using a 1-D hydrological model. Shindell et al. [2004] diagnosed the wetland spatial distribution using thresholds for climate parameters. Kaplan [2002] used an algorithm combining topography with calculated soil moisture. The goal of our study is to separate the contribution of area from that of flux density in the seasonal and interannual variability of $\mathrm{CH}_{4}$ emissions by wetlands over the past decade. To do so, we use two models: the ORCHIDEE global vegetation model [Krinner et al., 2005] and the process-oriented wetland emission model of Walter et al. [2001b]. We optimize some parameters using a dual constraint approach. The parameters controlling the flux density were optimized against site-level observations. The parameters controlling the seasonal cycle of wetland area in each region were optimized using a global remote sensing data set of flooded area [Prigent et al., 2001, 2007] and atmospheric inverted fluxes [Bousquet et al., 2006]. The optimized $\mathrm{CH}_{4}$ emission model was then integrated globally over the period 1993-2000 to separate the role of climateinduced varying area from varying flux density in the seasonal and interannual variability of wetland $\mathrm{CH}_{4}$ emissions over the globe.

\section{Methodology and Experimental Design}

\subsection{Methane Production at the Site Level}

[4] We used the process-based model developed by Walter et al. [2001a] and hereafter referred as W01. This model simulates methane flux densities from natural wetlands and calculates methanogenesis in the saturated deeper soil horizons, methanotrophic oxydation in the aerated upper soil, and upward transport by diffusion, ebullition and/or plant-mediated transport [Walter and Heimann, 2000]. In the original $\mathrm{W} 01$ formulation, the methane production rate

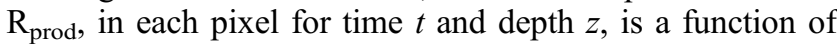
NPP and temperature given by

$$
R_{\text {prod }}(t, z)=R_{0} * f(N P P) * f(T(t, z)) * Q_{10}^{\frac{T(t, z)-T_{\text {mean }}}{10}}
$$

[5] The base rate of methanogenesis $\mathrm{R}_{0}\left(\mu \mathrm{mol} \mathrm{L} \mathrm{L}^{-1} \mathrm{~h}^{-1}\right)$ provides the amount of substrate available for methanogenesis. $\mathrm{f}(\mathrm{NPP})$ (dimensionless) is a function describing the seasonal fluctuations of the available substrate as well as its vertical distribution; this function is based on the seasonal cycle of NPP, and $\mathrm{f}(\mathrm{T})$ (dimensionless) is a step function equal to 0 if $\mathrm{T}(\mathrm{t}, \mathrm{z})<0^{\circ} \mathrm{C}$ and equal to 1 in all other cases; if the soil temperature drops below $0^{\circ} \mathrm{C}$ in one of the soil layers, there can be no methane production from this specific layer. This function only controls the ability of a specific soil layer to produce or not $\mathrm{CH}_{4}$. The $\mathrm{Q}_{10}$ parameter then defines the temperature dependency of methane production. The strategy of W01 was to calibrate the value of $R_{0}$ using data from six field sites, regressing $R_{0}$ versus soil temperature and NPP. There is, however, no direct processrelated relationship between NPP and $\mathrm{R}_{0}$ [Christensen et al., 2003; Conrad, 1989; Whiting and Chanton, 1993] except, perhaps for the exudation of sugars by roots which should be in lockstep with NPP [Hütsch et al., 2002]. Regardless, some previous studies have shown that the contribution of recent photosynthates to emissions is relatively low [i.e., King and Reeburgh, 2002].

[6] We modified the global calculation of $\mathrm{R}_{\text {prod }}$ according to equation (2) and replaced $R_{0}$ by a linear function of the labile soil carbon pool, $\mathrm{C}_{\mathrm{L}}$, as suggested by Cao et al. [1996] and Khvorostyanov et al. [2008]. Daily values of $\mathrm{C}_{\mathrm{L}}$ (expressed in $\mu \mathrm{mol} \mathrm{dm}^{-2}$ ), and some other inputs necessary for $\mathrm{W} 01$, are computed at each grid point by the ORCHIDEE global vegetation model [Krinner et al., 2005] run here in a non-water-stress configuration (see section 2.2). The base rate of methanogenesis $\left(\alpha_{0}\right.$, in $\left.\mathrm{dm}^{-1} \mathrm{~h}^{-1}\right)$ is a parameter that we have optimized. In equation (2), we have kept the function that vertically distributes the carbon in the soil, $f_{\text {org }}(\mathrm{z})$, which was part of $\mathrm{f}$ (NPP) in equation (1), because this distribution cannot be computed by ORCHIDEE.

$$
R_{\text {prod }}(t, z)=\alpha_{0} * f_{\text {org }}(z) * C_{L}(t) * f(T(t, z)) * Q_{10}^{\frac{T(t, z)-T_{\text {mean }}}{10}}
$$

[7] We have also optimized the $\mathrm{Q}_{10}$ value, a parameter which was initially set to 6 at all sites and even globally by W01, although its reported values in the literature range from 1.6 to 16 [Valentine et al., 1994]. This large reported range encompasses the temperature response of at least two processes: the substrate production and methanogenesis itself. Studies which measured $\mathrm{Q}_{10}$ for methanogenesis only report values in the range 1.2 to 3.5 [Conrad, 1989; Kelly and Chynoweth, 1981]. Thus the temperature dependency for methanogenesis derived from $\mathrm{C}_{\mathrm{L}}$ is expected to be different than the one regressed from NPP by W01. We decided not to optimize the metanotrophy-related parameters and hence to restrict our calibration only to the flooded phase of the wetlands, i.e., when the water table depth reaches soil surface and methanotrophy can be neglected (see details in sections 2.2 and 2.3).

\subsection{Simulations Carried Out With the ORCHIDEE Global Vegetation Model}

[8] We calculated the $\mathrm{CH}_{4}$ flux density over each wetland grid point on the basis of our updated version of the model developed by W01. Key input data are the water table depth, 
Table 1. Sites Selected for the Optimization of the Two Parameters Chosen ${ }^{\mathrm{a}}$

\begin{tabular}{|c|c|c|c|c|c|c|}
\hline Site Name & Coordinates & Reference & $\begin{array}{c}\text { Chosen } \\
\left(\alpha_{0}, \mathrm{Q}_{10}\right) \text { Pair }\end{array}$ & $\left(10^{-6} \mathrm{~m}^{-1}\right.$ month $\left.^{-1}\right)$ & $\mathrm{Q}_{10}$ & $\begin{array}{c}\text { RMSE } \\
\left(\mathrm{mg} \mathrm{m}^{-2} \text { month }^{-1}\right)\end{array}$ \\
\hline \multirow[t]{6}{*}{ Abisko } & $68^{\circ} \mathrm{N}, 19^{\circ} \mathrm{E}$ & $\begin{array}{l}\text { M. Jackowicz-Korczynski } \\
\text { (unpublished data, 2006) }\end{array}$ & Optimal & 2.63 & 2.60 & 1128 \\
\hline & & & Pair with highest $\alpha_{0}$ & 3.94 & 1.60 & 1194 \\
\hline & & & Pair with highest $\mathrm{Q}_{10}$ & 1.84 & 4.00 & 1153 \\
\hline & & & Pair with lowest $\alpha_{0}$ & 1.66 & 4.00 & 1212 \\
\hline & & & Pair with lowest $Q_{10}$ & 3.94 & 1.40 & 1201 \\
\hline & & & Mean & $2.80( \pm 0.98)$ & $2.72( \pm 1.12)$ & 1178 \\
\hline \multirow{6}{*}{ Michigan } & $42^{\circ} \mathrm{N}, 84^{\circ} \mathrm{W}$ & Shannon and White [1994] & Optimal & 2.45 & 3.20 & 1791 \\
\hline & & & Pair with highest $\alpha_{0}$ & 2.98 & 2.60 & 1946 \\
\hline & & & Pair with highest $\mathrm{Q}_{10}$ & 1.93 & 4.00 & 1942 \\
\hline & & & Pair with lowest $\alpha_{0}$ & 1.93 & 4.00 & 1942 \\
\hline & & & Pair with lowest $\mathrm{Q}_{10}$ & 2.89 & 2.60 & 1929 \\
\hline & & & Mean & $2.44( \pm 0.45)$ & $3.28( \pm 0.63)$ & 1910 \\
\hline \multirow[t]{7}{*}{ Panama } & $9^{\circ} \mathrm{N}, 80^{\circ} \mathrm{W}$ & $\begin{array}{l}\text { Keller [1990] } \\
\text { (data used from Walter publication) }\end{array}$ & Optimal & 13.75 & 1.20 & 5592 \\
\hline & & & Pair with highest $\alpha_{0}$ & 14.89 & 1.20 & 5834 \\
\hline & & & Pair with highest $\mathrm{Q}_{10}$ & 13.40 & 2.60 & 6042 \\
\hline & & & Pair with lowest $\alpha_{0}$ & 12.26 & 1.20 & 5980 \\
\hline & & & Pair with lowest $\mathrm{Q}_{10}$ & 13.75 & 1.20 & 5592 \\
\hline & & & Mean & $13.61( \pm 0.84)$ & $1.48( \pm 0.56)$ & 5808 \\
\hline & & & Added pair & 13.32 & 3.2 & 6174 \\
\hline
\end{tabular}

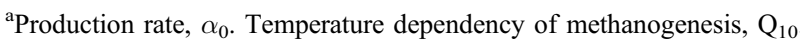

the soil temperature profile, and the labile soil carbon. For the water table depth, we made the assumption that it remains close to soil surface all year-round. This is the main hypothesis of our work: $\mathrm{CH}_{4}$ emissions by wetlands are dominated by the time periods during which the water table depth is at the surface. This assumption results from the use in the following (section 3.1) of remote sensing data which only detects water-logged areas [Prigent et al., 2001, 2007]. Soil temperature and carbon were computed by the global vegetation model ORCHIDEE [Krinner et al., 2005]. In ORCHIDEE, the soil temperature profile is calculated with a seven layers scheme and soil carbon depends on plant functional type and climate. We ran a global $1^{\circ} \times 1^{\circ}$ simulation assuming no water stress at any grid point in order to better represent the wetlands soil carbon (via better representation of NPP) and soil temperature computation: soil water content was prescribed at its maximum value throughout the entire length of the simulation. ORCHIDEE was forced with the present-day vegetation map of Loveland et al. [2000], the soil color map of Zobler [1999] for soil albedo, and the hourly climate forcing data of $\mathrm{NgO}-\mathrm{Duc}$ et al. [2005]. A spin-up run of several thousands of years was run to bring all carbon pools to their long-term equilibrium values. The 1993-2000 interannual simulation was then carried out. Since there is no specific plant functional type (PFT) for wetlands in ORCHIDEE, any flooded PFT (boreal, temperate and tropical forest or grassland) is assumed to be a potential wetland. Crops areas, however, are excluded in our calculations of $\mathrm{CH}_{4}$ emission and so are rice paddies (not represented in ORCHIDEE). Oxygen limitations on plant growth are not accounted and the simulated wetland NPP is likely to be high-biased. Other inputs of the Walter's model are root depth, soil depth, and the efficiency of plant-mediated transport. These data were derived by matching the 11 plant functional types of ORCHIDEE with the biome-specific values given by W01.

\subsection{Site-Level Model Optimization}

[9] The $\alpha_{0}$ and $\mathrm{Q}_{10}$ parameters have been optimized against local time series of $\mathrm{CH}_{4}$ flux measurements at three different sites listed in Table 1 in a strategy similar to that of Petrescu et al. [2008]. These sites are a bog site in northern Finland (the Abisko site, M. Jackowicz-Korczynski, unpublished data, 2006), a peatland site in Michigan [Shannon and White, 1994], and a swamp site in Panama [Keller, 1990]. They represent the three main categories of wetland areas as defined by Fung et al. [1991] and Cao et al. [1996] as the boreal bogs $\left(>50^{\circ} \mathrm{N}\right)$, the temperate bogs $\left(20^{\circ} \mathrm{N}-50^{\circ} \mathrm{N}\right)$, and the tropical swamps $\left(30^{\circ} \mathrm{S}-20^{\circ} \mathrm{N}\right)$, respectively.

[10] We first sampled the output from the global simulation of ORCHIDEE (described above) at the location of each calibration site. $\mathrm{CH}_{4}$ emissions were then calculated and parameters $\alpha_{0}$ and $\mathrm{Q}_{10}$ were adjusted in order to minimize the root mean square error (RMSE) between observed and modeled monthly emissions. Optimization was only carried out at time periods during which the water table depth was at the surface or above to be consistent with our main hypothesis (section 2.2). We assume, too, that there is no longer delay than a few days between potential emissions and the beginning of inundation. Figure 1 provides, for Abisko, a map of the RMSE in the $\alpha_{0}$ and $\mathrm{Q}_{10}$ plane. This map, or cost function to be minimized, shows that the $\left(\alpha_{0}, \mathrm{Q}_{10}\right)$ couple corresponding to absolute minimum of RMSE (as reported in Table 1) is located in a flat "valley" of $\left(\alpha_{0}, \mathrm{Q}_{10}\right)$ couples that all share a RMSE close to the minimum $(10 \%$ above absolute minimum area is shaded in the Figure 1). In order to derive an uncertainty range on $\alpha_{0}$ and $\mathrm{Q}_{10}$ parameters value that will be propagated into regional $\mathrm{CH}_{4}$ flux calculations, we also tested four other couples $\left(\alpha_{0}\right.$, $\left.\mathrm{Q}_{10}\right)$ within the low-RMSE valley. These couples have the highest $\alpha_{0}$, the highest $\mathrm{Q}_{10}$, the lowest $\alpha_{0}$, or lowest $\mathrm{Q}_{10}$ values, respectively, within the $\mathrm{RMSE} \leq 1.1 * \mathrm{RMSE}_{\text {min }}$ 


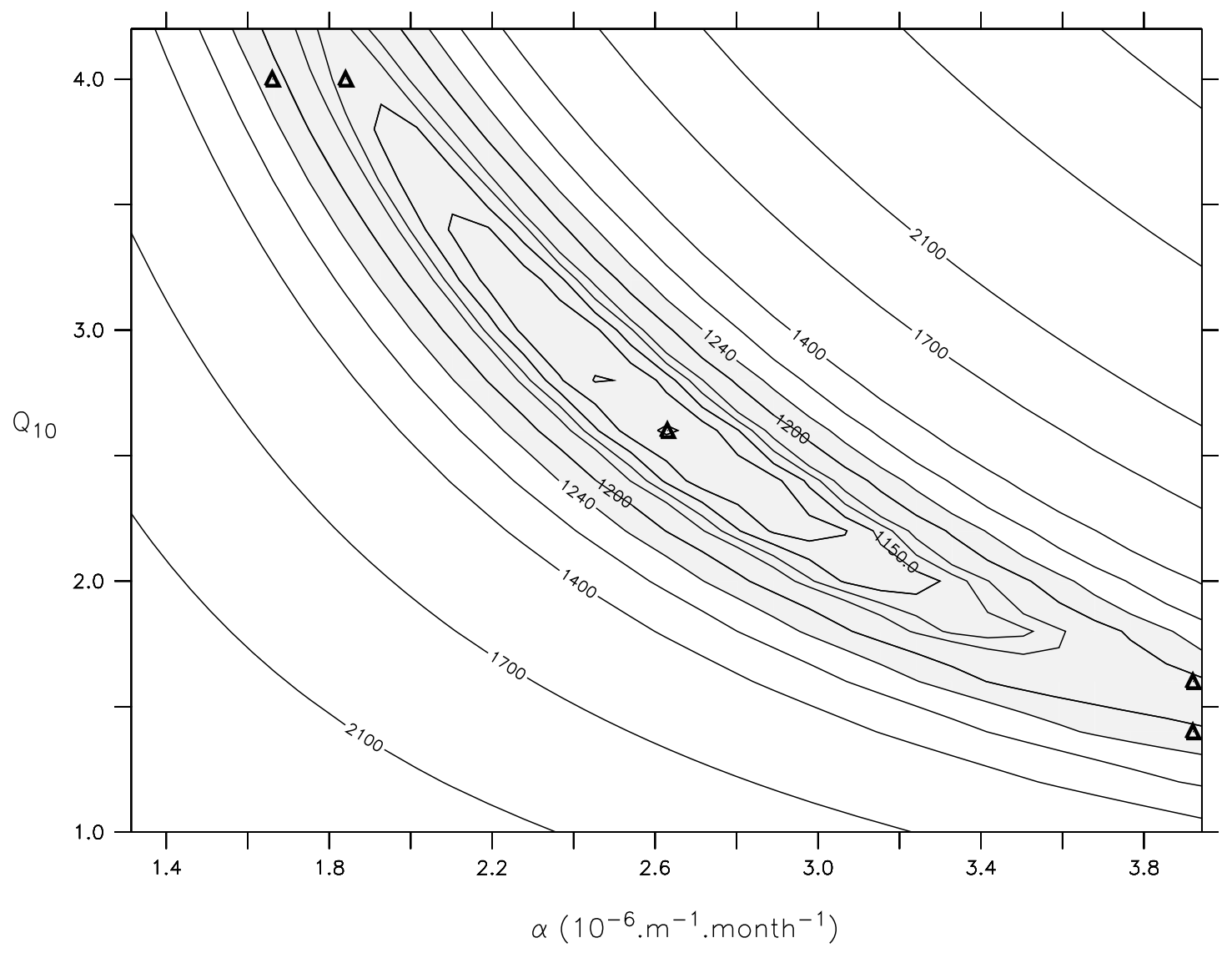

Figure 1. Root mean square error (RMSE) in $\mathrm{mg} \mathrm{CH}_{4} \mathrm{~m}^{-2}$ month ${ }^{-1}$ between modeled and observed daily $\mathrm{CH}_{4}$ fluxes at Abisko $\left(68^{\circ} \mathrm{N}, 19^{\circ} \mathrm{E}\right)$ for different pairs of our calibration parameters: $\mathrm{Q}_{10}$ is the temperature dependency of methanogenesis, and $\alpha_{0}$ is the production rate. Gray part represents $\left(\alpha_{0}, \mathrm{Q}_{10}\right)$ pairs with a RMSE lower than the absolute minimum of RMSE $+10 \%$. Black triangles symbolize both the optimal pair and additional pairs used to test the sensibility of our results.

valley. These different pairs are reported in Table 1, are represented by triangles in Figure 1, and will be used in the following to estimate error ranges for the simulated fluxes.

[11] At both the Abisko and Michigan sites, the $Q_{10}$ value is close to 3 , i.e., half the value chosen by W01, but close to the maximum value measured for methanogenesis [Conrad, 1989; Kelly and Chynoweth, 1981]. At the tropical (Panama) site, the optimized $\mathrm{Q}_{10}$ is found to be only of $1.48 \pm 0.56$, and this low value is rather well constrained by the flux data. It is also imposed by the lowest bound of the range given by Conrad [1989]. This low $\mathrm{Q}_{10}$ value results from the anticorrelation between temperature and flux density at this specific site: when temperature increases, flux density decreases and vice versa. Because we are looking at only one site that may not be representative of the whole tropics, and since having a higher $\mathrm{Q}_{10}$ in the tropics could change the relative importance of the flooding mechanism in terms of its contribution to variability of $\mathrm{CH}_{4}$ emission, we have chosen another $\left(\alpha_{0}, \mathrm{Q}_{10}\right)$ pair to be tested, with a $\mathrm{Q}_{10}$ value that is closer to the boreal one and the associated $\alpha_{0}$ that minimizes RMSE (Table 1).

[12] Contrary to $\mathrm{Q}_{10}$, the optimized value of $\alpha_{0}$ is larger for the tropical site than for the other sites (by a factor of $\sim 5)$. This order of magnitude between the tropical site and the others concerning the amount and the quality of substrate is consistent with what Walter and Heimann [2000] also discussed for $\mathrm{R}_{0}$. The larger discrepancy between sites at different latitudes may also result from the very weak number of carbon soils pools in ORCHIDEE (e.g., not accounting for the exudates pool) and the simple way in which carbon dynamics is computed.

[13] Figure 2 (left) (Figures 2a, 2c, and 2e) compares the seasonal cycle of simulated and observed $\mathrm{CH}_{4}$ emissions at each site, with their respective error bars when available. At the Abisko site, the amplitude of the seasonal cycle of the $\mathrm{CH}_{4}$ flux, as well as the length of the emission season, are well captured by the optimized model. However, the peak of $\mathrm{CH}_{4}$ emissions is about 1 month early compared to the site observations. The ORCHIDEE model lacks a parameterization of frozen soils, which qualitatively explains this earlier maximum. At the temperate (Michigan) site, the modeled flux agrees quite remarkably with the observed one.

[14] At the tropical (Panama) site, the optimized model shows no seasonal cycle of $\mathrm{CH}_{4}$ flux over the 7 month flooded period of selected observations, although the data suggest higher emissions from October to November $\left(\sim 20 \mathrm{gCH}_{4} / \mathrm{m}^{2} /\right.$ month) than from May to August $\left(\sim 12 \mathrm{gCH}_{4}\right.$ $\mathrm{m}^{-2}$ month $\left.^{-1}\right)$. Errors associated to the observed fluxes are 
Site scale (Adjustment of $\alpha$ and $\mathrm{Q}_{10}$ values)

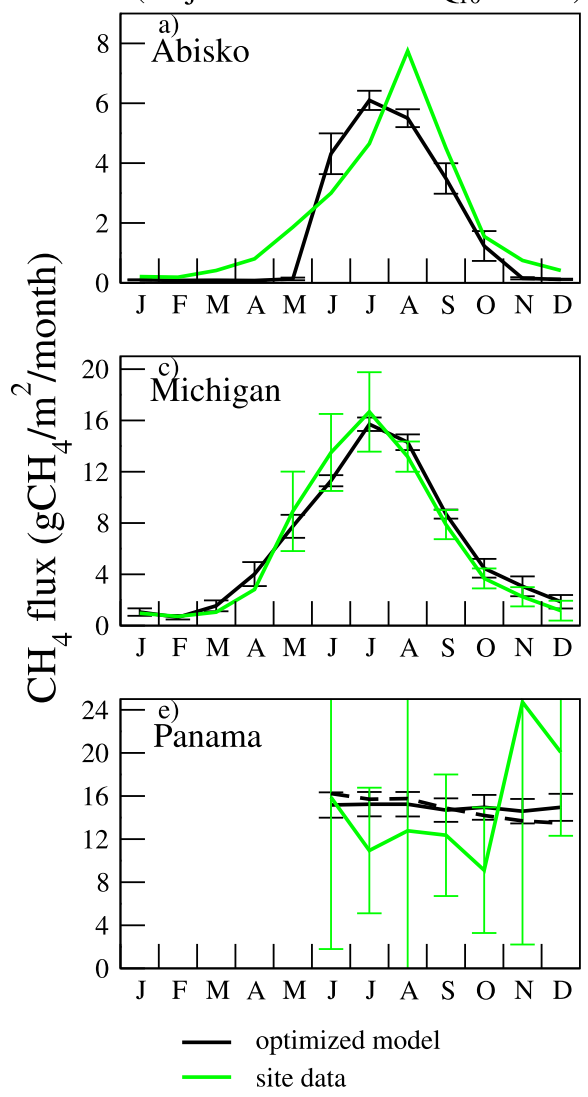

Semi-hemispeheric scale

(Adjustment of $\beta$ value)
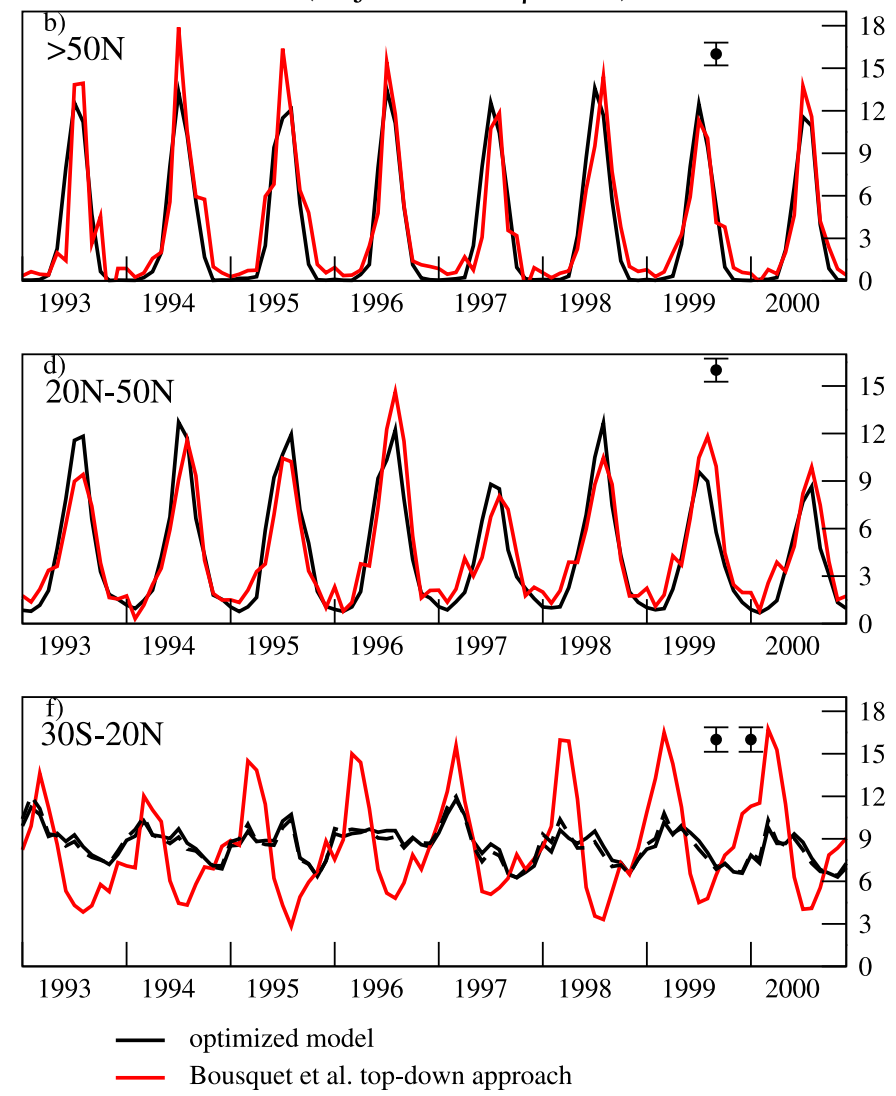

Figure 2. (left) Mean seasonal cycle of methane emission $\left(\mathrm{g} \mathrm{CH}_{4} \mathrm{~m}^{-2} \mathrm{month}^{-1}\right)$ observed and simulated at three different wetland sites located in the (top) boreal, (middle) temperate, and (bottom) tropical regions, respectively. The adjustment at site scale is done between the simulated fluxes (black curve) and sites data (green curve) for years where the last one is observed (or for mean year if the observations are done on many years). The adjustments are done for periods where the water table depth is close to the soil surface (i.e., all the year for boreal and temperate sites and only March-December period for tropical site).The different pairs of $\left(\alpha_{0}, \mathrm{Q}_{10}\right)$ obtained with the optimization procedure are used to define error bars on the simulated fluxes. Fluxes obtained at Panama site for the 6th tropical pair with increased $\mathrm{Q}_{10}(3.2)$ are plotted in dashed. Error bars in the observations were only available for two sites (Michigan and Panama). (right) Interannual variations of the seasonal cycle of methane emitted from the natural wetland areas (Tg $\mathrm{CH}_{4} /$ month) simulated (black line) and resulting from the Bousquet et al. [2006] inversion approach (red line) for three different latitudinal bands ((top) boreal, (middle) temperate, and (bottom) tropical). The different triplets of $\left(\alpha_{0}, \mathrm{Q}_{10}, \beta_{\text {area }}\right)$ are used to draw error bars. As above, emissions obtained for tropics using an increased $\mathrm{Q}_{10}$ (3.2) are plotted in dashed.

too large to provide a tight constraint of the model parameters. At this site, ORCHIDEE simulates no seasonal variations of NPP, nor of the labile carbon and of soil temperature, which is the reason why the modeled $\mathrm{CH}_{4}$ flux remains constant all year-round at this site.

\section{Methane Emission Upscaling to the Global Level}

\subsection{Satellite Observed Wetland Area Distribution}

[15] We integrated our optimized emission model over the globe, forced with outputs from our $1^{\circ} \times 1^{\circ}$ ORCHIDEE run. The seasonal and interannual variability of wetland extent comes from the remote sensing product developed by Prigent et al. [2001, 2007] at a horizontal resolution of $0.25^{\circ}$ by $0.25^{\circ}$. This data set provides us with the fractional inundated area per pixel and per month, and covers the 1993-2000 time period. It therefore quantifies the existence of stagnant water throughout the globe, but not of methane production (that we compute according to equation (2)). It is the only data set (to our knowledge) providing global and temporal information on the variability of natural wetland areas. It is constructed using a combination of satellite data including passive microwave observations and a linear 
a) Mean P07 Surfaces - (Lakes + Rice paddies)

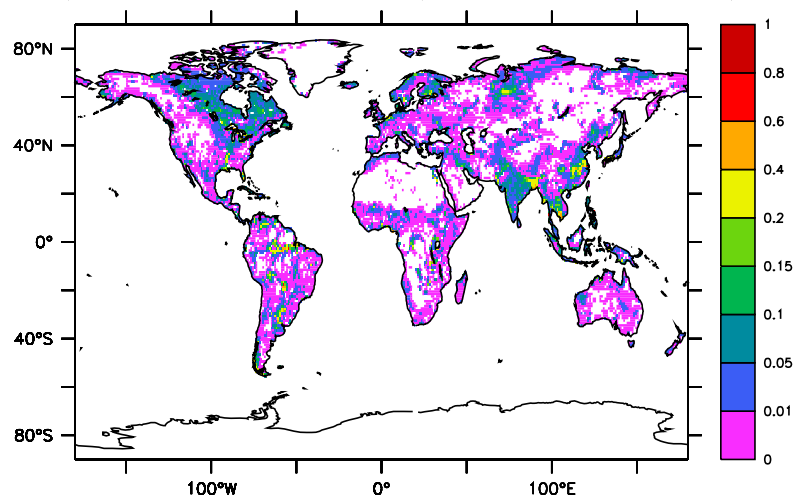

c) Number of inundated months

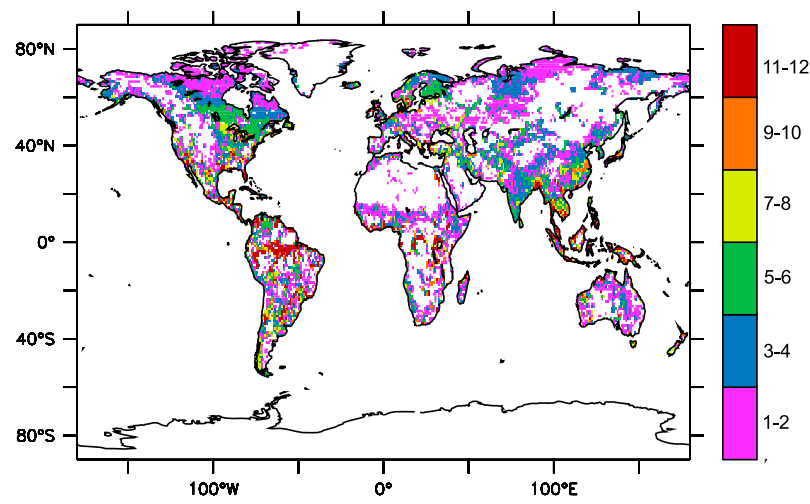

b) Year-to-year standard deviation

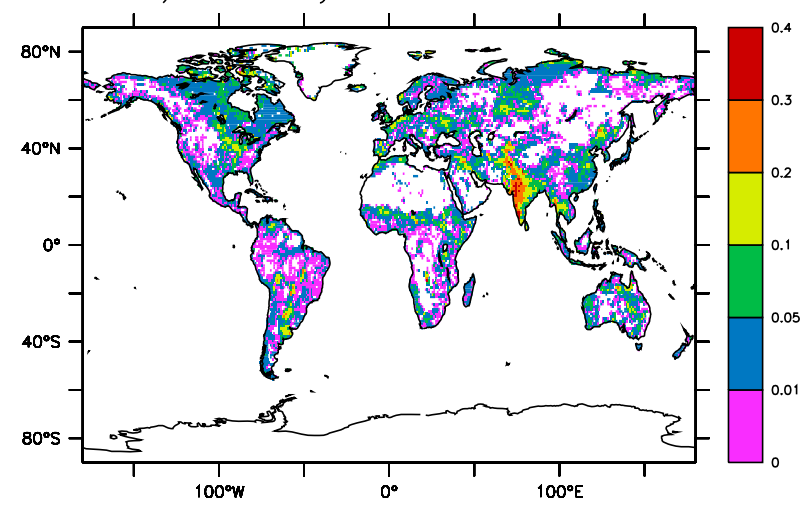

d) Month of maximum inundation

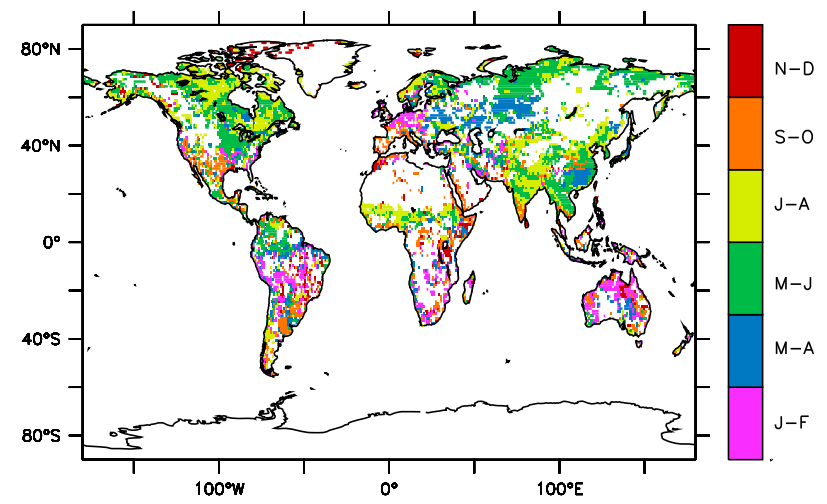

Figure 3. Prigent et al. [2001, 2007] data set interpolated at $1^{\circ}$ resolution and filtered in order to exclude lakes (IGBP land cover data set [Loveland et al., 2000]) and rice paddies areas [Matthews et al., 1991]: (a) global map of wetland extent, (b) year-to-year variability (dimensionless), (c) the mean annual number of inundated months, and (d) timing of maximun flooding in calendar month.

mixture model to account for vegetation [Prigent et al., 2001, 2007]. For the boreal regions, as the microwave measurements are sensitive to the snow cover, snow masks were used to edit the results and avoid any confusion with snow covered pixels. The weekly North Hemisphere and South Hemisphere snow mask from the National Snow and Ice Data Center (NSIDC) is adopted and averaged on a monthly basis [Armstrong and Brodzik, 2005].

[16] We have filtered the Prigent et al. [2001, 2007] data set interpolated at $1^{\circ}$ resolution in order to exclude lakes (IGBP land cover data set [Loveland et al., 2000]). In lakes, most of the $\mathrm{CH}_{4}$ produced in the sediment is oxydized before reaching the surface [Walter and Heimann, 2000], except maybe for Arctic thermokarst lakes that are subject to warming in winter [Zimov et al., 1997; Walter et al., 2006] and for some tropical dams established over flooded forests [Abril et al., 2005]. We have also excluded all rice paddy areas [Matthews et al., 1991]. The resulting global map of wetland extent is shown in Figure 3, together with its interannual variability, the mean annual number of inundated months, and the timing of maximum flooding. More detailed information concerning the seasonal and interannual behavior of specific regions can be found in the work of Papa et al. [2006] and Papa et al. [2007, 2008a] for the Indian subcontinent and the boreal regions, respectively.

\subsection{Optimization Approach}

[17] Flooded areas from Prigent et al. [2007], once filtered for lakes and rice paddies, were further adjusted to only retain those inundated pixels that are $\mathrm{CH}_{4}$ emitters. Flooded river valleys, for example, or inundated nonorganic soils will not emit $\mathrm{CH}_{4}$. This implies the active wetland area to be smaller than the satellite-observed area. At the face value, the multisatellite approach has difficulty to detecting small, isolated water patches in areas with a large dry fraction. This may imply the active wetland area to be higher than satellite observed. We thus have more confidence on the variability, on seasonal and year-to-year scales, of flooded area than on the mean average value. Accordingly, we tuned the flooded area by a regionally uniform multiplier $\beta_{\text {area }}$ that is calculated in order to minimize the RMSE between our bottom-up model fluxes and the top-down monthly fluxes aggregated into large latitudinal bands (boreal, temperate, and tropical; see below) from the 
Bousquet et al. [2006] atmospheric inversion (hereafter referred to as B06).

[18] The B06 inverse modeling quantitatively links atmospheric $\mathrm{CH}_{4}$ measurements and regional sources and sinks. For the period 1984-2003, the $\mathrm{CH}_{4}$ concentration responses to the action of $\mathrm{OH}$ sinks and regional surface sources were simulated for each month with the threedimensional chemistry transport model LMDZ-INCA [Hauglustaine et al., 2004]. The model was forced with interannual analyzed winds [Uppala et al., 2005] and interannually varying $\mathrm{OH}$ concentrations as constrained by methyl-chloroform observations [Bousquet et al., 2005]. Emissions of $\mathrm{CH}_{4}$ from different regions of the globe by distinct processes, together with the photochemical sinks, were inferred and their uncertainties reduced by matching atmospheric observations within their uncertainties in a Bayesian formalism [Bousquet et al., 2005]. Long-term measurements of the ${ }^{13} \mathrm{C} /{ }^{12} \mathrm{C}$ ratio in $\mathrm{CH}_{4}\left(\delta^{13} \mathrm{C}_{-} \mathrm{CH}_{4}\right)$ were also used as an additional constraint on the partitioning of microbial-, biomass-burning-, and fossil-fuel-related $\mathrm{CH}_{4}$ sources. Prior sources were from inventories [Fung et al., 1991; Van der Werf et al., 2003, 2004; Olivier and Berdowski, 2001]. Note that no interannual variability was assigned to the prior sources, so interannual variations of atmospheric concentrations were built through the inversion procedure. B06 performed a control inversion, which is used in this work, supplemented by an ensemble of 17 sensitivity inversions (varying a priori error of regional fluxes, etc.). B06 shows a very good fit to observations both for interannual and seasonal variations, demonstrating that the seasonality of inverted emissions is consistent with atmospheric measurements of methane.

[19] The optimization of $\beta_{\text {area }}$ was carried out for three major latitudinal zones. Each one consists of the grouped continental regions that were used in the TRANSCOM3 model intercomparison experiment [Gurney et al., 2002]. This choice is made to be consistent with the top-down approach results (B06) used. The boreal band includes Boreal North America, Europe, and Boreal Eurasian TRANSCOM regions. The temperate band includes temperate North America, northern Africa, and temperate Eurasia. The tropical band includes South America, southern Africa, tropical Asia, and Australia. Each of the three zones has a separate and unique set of methane flux parameters ( $\alpha$ and $\mathrm{Q}_{10}$ ) that is derived from the optimizations carried out at the site level located within each band (see section 2.3). This breakdown into three categories sharing the same parameters is obviously idealized compared to reality where wetlands cover a large diversity of ecosystems with distinct Redox, $\mathrm{pH}$, or nutrient status [Mitsch and Gosselink, 2000]. However, given the lack of site-level data, it would have been unreasonable to try to include more details.

[20] For each major group of regions and each of the five $\left(\alpha_{0}, \mathrm{Q}_{10}\right)$ pairs selected (six in the tropics) in our sensitivity tests (section 2.3), we have optimized $\beta_{\text {area }}$ for each individual year (1993 to 2000). The $\mathrm{CH}_{4}$ fluxes presented hereafter were calculated, for each $\left(\alpha_{0}, \mathrm{Q}_{10}\right)$ pair, using three different values of $\beta_{\text {area }}$ : the mean over the 8 years and the mean \pm 1 standard deviation. The optimized values of $\beta_{\text {area }}$ are $0.68 \pm 0.08,1.19 \pm 0.17$, and $1.04 \pm 0.12$ for the boreal $\left(>50^{\circ} \mathrm{N}\right)$, the temperate $\left(20^{\circ} \mathrm{N}-50^{\circ} \mathrm{N}\right)$, and the tropical $\left(30^{\circ}\right.$ $\left.\mathrm{S}-20^{\circ} \mathrm{N}\right)$ latitudinal belts, respectively. The sixth tropical pair of $\left(\alpha_{0}, \mathrm{Q}_{10}\right)$ chosen, with increased $\mathrm{Q}_{10}$ value, does not change the $\beta_{\text {area }}$ value. In the temperate belt, $\beta_{\text {area }}$ is larger than one, suggesting that emitting areas should be increased compared to the prior satellite value. This may reflect wet areas that have not been detected by the satellite product, or wet areas where the water table depth lies just below the soil surface.

\subsection{Comparison With Bousquet et al. [2006] Top-Down Approach}

[21] The monthly emission of methane per pixel, $\mathrm{f}_{\mathrm{CH} 4}(\mathrm{x}, \mathrm{t})$, in $\mathrm{g} \mathrm{CH}_{4} /$ month, is finally calculated according to

$$
f_{C H 4}(x, t)=\left[\beta_{\text {area }} * S(x, t)\right] * F_{C H 4}(x, t)
$$

where $\mathrm{S}(x, t)$ and $\mathrm{F}_{\mathrm{CH} 4}(x, t)$ are the fraction of the pixel $x$ that is inundated during month $t$ and the flux density for pixel $x$ and month $t$, respectively. $\mathrm{F}_{\mathrm{CH} 4}(x, t)$ is taken from the output of W01 after modification of methanogenesis production rates following equation (2) and optimization of $\alpha_{0}$ and $\mathrm{Q}_{10}$. The resulting space and time varying maps of wetland $\mathrm{CH}_{4}$ fluxes are thus compatible with the measured $\mathrm{CH}_{4}$ fluxes at the three calibration sites, the satellite observed patterns of flooded surfaces, and the latitudinally averaged B06 inversion fluxes. Figure 2 (right) (Figures 2b, 2d, and 2f) shows the seasonal and interannual variability of wetland emissions for each latitudinal band. The agreement between $\mathrm{f}_{\mathrm{CH}}(x, t)$ and the inversions of B06 is very good at boreal and temperate latitudes, although the minimum value of the top-down $\mathrm{CH}_{4}$ flux in winter is always larger than the one we simulate. In the tropical belt, however, there is no agreement between the topdown and bottom-up estimates, even after adjustment of $\beta_{\text {area }}$. Not only is the amplitude of the seasonality of our simulated $\mathrm{f}_{\mathrm{CH} 4}(\mathrm{x}, \mathrm{t})$ much smaller than the one estimated by B06 ( $50 \%)$, but the timing of maximum emissions is shifted.

[22] If we focus, for instance, on the tropical South American TRANSCOM region, variations of $\mathrm{CH}_{4}$ emissions from B06 follow precipitation (the correlation $\left(\mathrm{r}^{2}\right)$ equals to 0.38 over $1993-2000$ ). This could be partly explained by nudging of the inversion results to their a priori flux temporality. The a priori flux of B06 comes from a combination of the Fung et al. [1991] flux density and the Matthews and Fung [1987] static data for wetland surface extent. $\mathrm{CH}_{4}$ emissions are maximum in the work of Fung et al. [1991] when monthly precipitation exceeds monthly potential evaporation. The inversion has changed the magnitude, but not the timing of the emissions. Oppositely, in the P07 area data set which underpins our bottom-up modeling, precipitation often precedes inundation by a few months. For example, over the tropical South American TRANSCOM region, we have calculated that the best correlation $\left(r^{2}=0.6\right)$ between rainfall and P07 wetland extent is obtained with a lag of 3 months. In these tropical regions, inundation, through the floodplain mechanisms, is likely due to precipitation events upstream. For a region as tropical South America, this may explain the shift of emissions between B06 and our approach. Discrepancy between B06 and our 

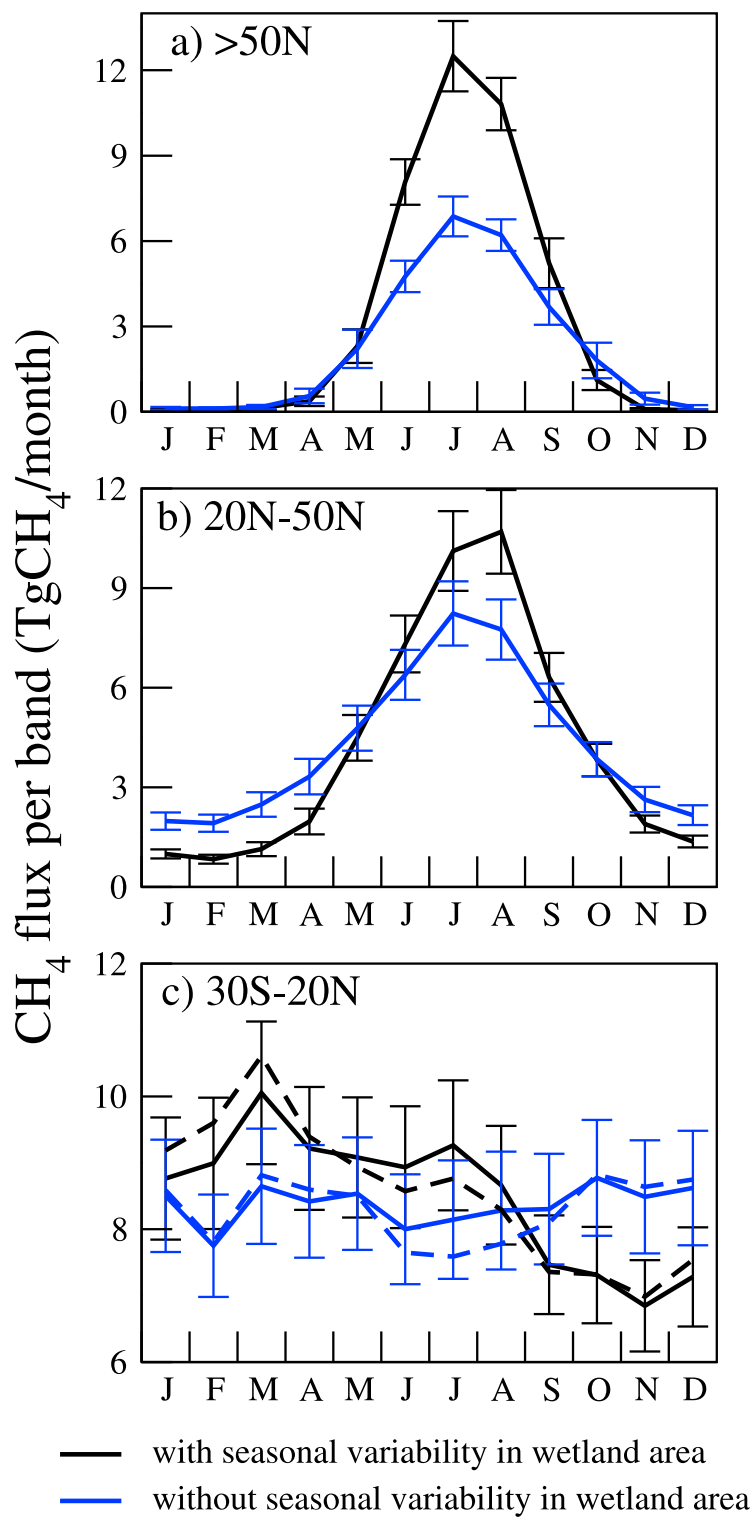

Figure 4. Mean seasonal cycle, averaged over the period 1993-2000, of methane emitted from the natural wetland areas $\left(\mathrm{Tg} \mathrm{CH}_{4}\right.$ month $\left.^{-1}\right)$ simulated for three different latitudinal bands ((a) boreal, (b) temperate, and (c) tropical). The VAR simulation, that accounts for the observed seasonal variations of wetland extent, is shown in black while the FIXED simulation that uses a prescribed mean seasonal cycle is drawn using the blue line. The different triplets $\left(\alpha_{0}, \mathrm{Q}_{10}, \beta_{\text {area }}\right)$ defined with the optimization procedure are used to draw the error bars. For tropics, VAR and FIXED simulations realized with an increased $\mathrm{Q}_{10}$ are in dashed.

results at larger space scales $\left(30^{\circ} \mathrm{S}-20^{\circ} \mathrm{N}\right.$ belt) could be also explained by the fact that the northern and southern hemisphere contributions to the flux are weighted differently in the different estimates of wetland area used [Matthews and Fung, 1987; Prigent et al., 2007]. Despite these differences, the total annual emissions coming from the tropics is of the same order of magnitude in both B06 and our approach.

\section{How Much Do the Fluctuations in Wetland Area Contribute to the Seasonal and Interannual Variability of $\mathrm{CH}_{4}$ Fluxes?}

[23] We have carried out three sensitivity simulations to assess the contribution of seasonal and interannual variations of wetland extent to the total $\mathrm{CH}_{4}$ wetland flux to the atmosphere. The first simulation, called VAR, is forced by the variable wetland extent of Prigent et al. [2001, 2007] over 1993-2000. The second simulation, called FIXED, is forced monthly by a fixed climatological wetland area (mean annual area or mean area over the emitting season). The third simulation called CLIM is forced by a climatological (averaged over the 8 years of satellite observations), seasonally variable, wetland area. The range of sensitivity tests with varied parameters (sections 2.3 and 3.2) are used to derive errors bars in those calculations. The percent change of total annual $\mathrm{CH}_{4}$ emissions (per latitude band per year) is used to evaluate the contribution of wetland extent variations at both time scales: seasonal and interannual.

\subsection{Annual Mean and Seasonal Variability (VAR Versus FIXED Simulations)}

[24] The mean seasonal cycle of wetland $\mathrm{CH}_{4}$ emissions, averaged over the period 1993-2000, is illustrated in Figure 4. A mean annual flux of $40.8 \mathrm{Tg} \mathrm{CH}_{4} \mathrm{yr}^{-1}$ is emitted by bogs in the boreal belt, of which $33.7 \%( \pm 2.9 \%)$ is attributed to the seasonal increase in flooded area, with larger emitting surfaces in July and August and almost no active surfaces from November to April. If we had prescribed, as W01 did previously, the maximum extent of wetland area to run our FIXED run instead of the mean value over the flooded season, we would have simulated a larger mean annual boreal $\mathrm{CH}_{4}$ flux, but the variability explained by changes in area would still have been larger than $30 \%$. If we use another metric for this evaluation: the variation of amplitude of the mean seasonal cycle (rather than the total annual flux) to measure the contribution of changing area to $\mathrm{CH}_{4}$ emissions, we obtain a decrease of $45.7 \%( \pm 0.6 \%)$ in amplitude from VAR to FIXED. In all cases, the contribution of wetland extent to methane emissions (annual values and seasonal cycle) is significant and range between 30 and $50 \%$.

[25] A flux of $51.0 \mathrm{Tg} \mathrm{CH}_{4} \mathrm{yr}^{-1}$ is emitted by wetlands in the temperate belt, but the contribution of area extent changes to the mean annual flux is close to $0 \%$. This results from reduced amplitude of the seasonal cycle of flooded areas and the longer emitting season in temperate regions that leads to increased winter values and decreased summer ones. For both temperate and boreal wetlands, the flux density is positively correlated with the extent: when the extent is maximum during summer, the density is also maximum mainly driven by temperature. This is why the VAR and FIXED fluxes are perfectly in phase (Figure 4). However, in the temperate belt, flux densities are not zero during winter unlike boreal regions. Thus, removing wetland seasonality (from VAR to FIXED simulations) results in an 
increase in wetland area during winter and a decrease during summer that compensate each other. This leads, however, to a decrease in mean seasonal cycle amplitude of $40.0 \%$ $( \pm 1.0 \%)$.

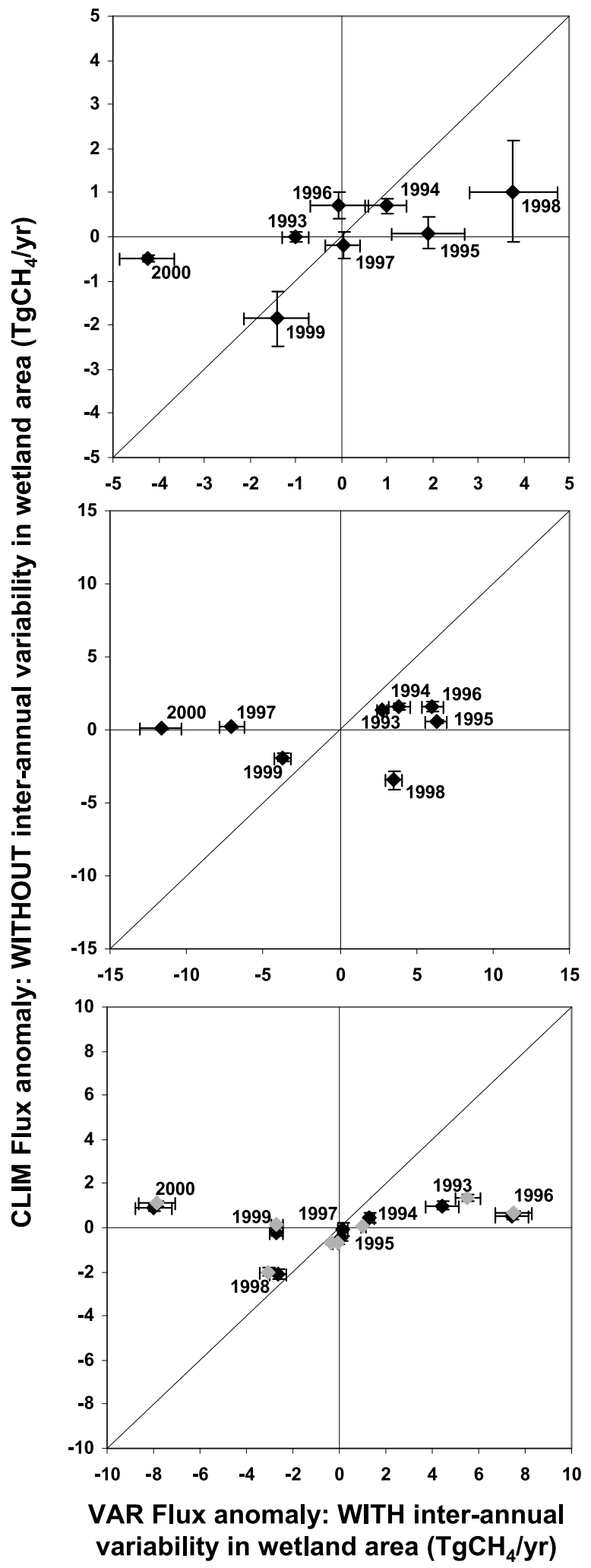

[26] For tropical wetlands where we simulate the largest annual $\mathrm{CH}_{4}$ flux $\left(\sim 102 \mathrm{Tg} \mathrm{CH}_{4} \mathrm{yr}^{-1}\right)$, the situation is quite similar: seasonal variations of the extent do not significantly contribute to the mean annual flux $(\sim 1.4 \% \pm 1.0)$. Accounting explicitly for variable area (VAR compared to FIXED) introduces a seasonality in the fluxes, with larger (smaller, respectively) fluxes during the February-August (September-January, respectively) period of the year, resulting in small changes of the annual mean but leads to a decrease of $66.4 \%( \pm 1.4 \%)$ for seasonal amplitude. The seasonality of tropical $\mathrm{CH}_{4}$ fluxes is hence dominated by the seasonality of wetland area (Figure 4), regardless of the value of $\mathrm{Q}_{10}$ : if it is low as derived from the optimization procedure or it is as large as that of the boreal regions.

\subsection{Interannual Variability (VAR Versus CLIM Simulations)}

[27] We now analyze the effect of interannually variable versus interannually fixed but seasonally variable wetland area. The CLIM flux anomalies are plotted versus the VAR ones in Figure 5 for each latitudinal band. In the three latitudinal bands, no simple relationship with good statistical significance (measured using a $r^{2}$ regression coefficient) that correlates the CLIM and the VAR anomalies was found. This indicates that interannual changes in wetland $\mathrm{CH}_{4}$ emissions result from a nontrivial combination between climate induced changes in flux densities and changes in wetland areas, with a little covariance between these two factors.

[28] The points that lie near the origin of the CLIM-VAR scatterplot exhibit a small interannuality and will therefore not be further discussed (e.g., years 1993, 1994, 1996, and 1997 in the boreal regions). The points that lie between the $x$ axis and the 1:1 line mark the years when the anomaly in $\mathrm{CH}_{4}$ flux is amplified by the anomaly in wetland area. The climate anomaly that drives an increase (resp. a decrease) in $\mathrm{CH}_{4}$ flux is at the same time driving a larger (a smaller, respectively) extent of emitting areas. Examples of this positive covariance between area and flux density are 1998 and 2000 in the boreal belt, during which $79.1 \pm 26.2 \%$ and

Figure 5. Evaluation of the impact of changes in wetland extent on the simulated annual methane emissions at the interannual time scale. Yearly anomalies (with respect to the mean over the years 1993 to 2000) of annual methane emissions ( $\mathrm{Tg} \mathrm{CH}_{4} \mathrm{yr}^{-1}$ ) simulated without accounting for interannual fluctuations of wetland extent (simulation CLIM) are plotted against the anomalies simulated in the VAR simulation. This is done for each of the three different latitudinal bands selected ((top) boreal, (middle) temperate, and (bottom) tropical). During the years that are located between the $x$ axis and the 1:1 line, the anomaly in $\mathrm{CH}_{4}$ flux is amplified by the anomaly in wetland area. Elsewhere the impacts of changing flux density and changing wetland extent have contradictory effects on the total anomaly simulated. The different triplets $\left(\alpha_{0}, \mathrm{Q}_{10}, \beta_{\text {area }}\right)$ defined by the optimization procedure are used to draw the error bars. For tropics, points obtained with increased $\mathrm{Q}_{10}$ are symbolized by gray markers. 
$88.3 \pm 0.6 \%$, respectively, of the total methane flux anomaly is explained by anomalies in wetland areas when compared to the climatology, the rest being caused by anomalous flux density. In the temperate belt, close to or more than $50 \%$ of the $\mathrm{CH}_{4}$ anomaly is explained by changes in area for years $1995(90.7 \pm 2.0 \%), 1996(73.7 \pm 3.6 \%)$, and $1999(49.9 \pm$ $1.1 \%)$. In the tropics, changes in area explain most of the interannual variability in wetland $\mathrm{CH}_{4}$ fluxes emissions, most of the points being next to the $x$ axis. Even with increased $\mathrm{Q}_{10}$, our conclusion is not altered (gray markers in Figure 5). Moreover, quantification of the contribution of wetland extent to interannual variability of $\mathrm{CH}_{4}$ emissions is independent of the chosen $\beta$.

[29] There are some years, however, in the boreal and temperate zones when climate anomalies drive increases (decreases, respectively) in $\mathrm{CH}_{4}$ flux per unit area, while they drive a decrease (increase, respectively) in wetland extent. Accounting for such a negative covariance therefore dampens or even compensates for the effects of changing flux density. In 1998, for example, in the temperate belt, climate forcing alone led to negative flux density anomalies, while the resulting flux shows a positive anomaly when variable area is considered. In 1999, in the boreal belt, the flux anomaly has a lower magnitude when the variability of area is included. The CLIM anomalies are quite similar between years 1996 and 2000 in the tropical zone (small anomalies), while the VAR anomalies between these 2 years are opposite in sign and quite large. All these examples suggest that climate variability can affect areas and flux densities in different and complex ways. The climate dependency of processes controlling inundated area (rainfall and potential evaporation) and $\mathrm{CH}_{4}$ flux density (labile carbon production and temperature) are indeed different. This finding is parallel to the observation that there is no simple relationship between wetland area and rainfall or temperature [Prigent et al., 2007], suggesting that nonclimatic factors, or other variables controlling the surface water budget may also play an important role in the establishment and resilience of wetlands (destruction of peat soils by fires like in Indonesia in 1997 [Page et al., 2002] or in the Moscow region in 2002). Flooding can occur in response to locally intense precipitation. However, they can also be driven by snowmelt or heavy precipitation at upstream locations [Prigent et al., 2007; Papa et al., 2007]. In these cases, inundation and precipitation are separated in both time and space. For instance, relations between precipitation, wetlands extent, and water storage (using GRACE satellite) were explored by Papa et al. [2008b].

[30] If we specifically focus on the year 1998, Dlugokencky et al. [2001] attributed the high positive flux anomaly in atmospheric $\mathrm{CH}_{4}$ content to wetlands located north of $30^{\circ} \mathrm{N}\left(\sim 11.6 \mathrm{Tg} \mathrm{CH}_{4} \mathrm{yr}^{-1}\right)$ and in the tropics $\left(\sim 13 \mathrm{Tg} \mathrm{CH}_{4} \mathrm{yr}^{-1}\right)$, while our calculations are quite different from those $\left(5.4 \mathrm{~T} \mathrm{Tg} \mathrm{CH}_{4} \mathrm{yr}^{-1}\right.$ and $-0.8 \mathrm{Tg} \mathrm{CH}_{4} \mathrm{yr}^{-1}$, respectively). If we assume their anomalies were most probably overestimated by up to $40 \%$ as the authors themselves seem to suggest, we end up with quite similar anomalies for northern wetlands but quite different and even oppositely sign values for the tropics. For wetlands located north of $30^{\circ} \mathrm{N}$, change in wetland extent explains almost all of the positive anomaly during the considered year (from VAR to CLIM the anomaly becomes close to zero or negative according to the parameters' value). Our negative anomaly in tropical regions results both from the changes in wetland extent (decrease) and in flux density (decrease). In our simulation, it is a negative anomaly in the active carbon stock that drives the simulated fluxes. This negative anomaly results from increased heterotrophic respiration (caused by increased surface temperature) that overcompensates the increased growth primary productivity and leads to decreased carbon accumulation. This negative anomaly is obtained even with a large $\mathrm{Q}_{10}$. In the original version of Walter et al.'s [2001a] model and in its adaptation used by Dlugokencky et al. [2001], the amount of substrate $\left(\mathrm{R}_{0}\right)$ is mainly dependent on temperature, and thus, flux densities always increase when temperature increases.

\section{Conclusion}

[31] We have developed a global process-based $\mathrm{CH}_{4}$ emission model forced globally by input from the ORCHIDEE global vegetation model and driven by varying climate. The modeled fluxes are calibrated at local scale against flux measurements from three sites, and at the scale of large latitude bands using remote sensing data on seasonally flooded areas. We showed that over the time period 1993-2000, variability in wetland area strongly influences in the seasonal and interannual variability of $\mathrm{CH}_{4}$ emissions. At the seasonal time scale, variable flooded area mainly plays a role in controlling variable fluxes at boreal latitudes $(\sim 30 \%)$. In the temperate regions and in the tropics, variations in area do not influence the annual emissions $(\sim 0 \%$ in the temperate zone and less than $2 \%$ in the tropics) but explain a large part of the seasonality amplitude. At the interannual time scale, however, variable area is the main source of interannual variability in the global $\mathrm{CH}_{4}$ wetland source at all latitudes, especially in the tropics. Because regional patterns of climate variability can affect in opposite (and nontrivial) ways the wetland area and the $\mathrm{CH}_{4}$ flux density, it is absolutely necessary to compute the changes in extent to correctly predict the current and future behavior of $\mathrm{CH}_{4}$ emissions in response to climate.

[32] We have, however, neglected variations of the water table depth, an important factor controlling $\mathrm{CH}_{4}$ fluxes [Liblik and Moore, 1997; Shurpali and Verma, 1998] in nonsaturated wetlands. Indeed, the wetland extent data set that we used does not sense those areas. Not accounting for this factor could (1) amplify the importance played by wetland areas fluctuations in our results and (2) explain some disagreement between our approach and top-down results in tropics where changes in the water table seem to dominate seasonal cycle of wetland $\mathrm{CH}_{4}$ emissions [Walter et al., 2001a]. Moreover, P07 inundation fractions can include areas where the water table is well above the soil surface such that oxidation can occur in a standing water column [Walter and Heimann, 2000]. In a following work, we can match information given by P07 and information about the value of water table depth given by satellite altimeters on continental water bodies. An improvement in 
W01 would also be necessary to account for the oxidation in a water column.

[33] Our approach could also be refined, since labile carbon has been computed by ORCHIDEE assuming soils to be water saturated all year long, while in reality, the plant production and soil carbon decomposition rates during the flooded and nonflooded period may be different. Moreover, we need to better account for the limitation of carbon decomposition under anoxic conditions in ORCHIDEE.

[34] Acknowledgments. This research was supported by the project Impact-Boreal, funded by the Agence Nationale pour la Recherche (ANR). We also thank M. Jackowicz-Korczynski and T.Christensen for the Abisko data. Computing support was provided by Commissariat à l'Energie Atomique (CEA).

\section{References}

Abril, G., F. Guérin, S. Richard, R. Delmas, C. Galy Lacaux, P. Gosse, A. Tremblay, L. Varfalvy, M. A. Dos Santos, and B. Matvienko (2005), Carbon dioxide and methane emissions and the carbon budget of a 10-year old tropical reservoir (Petit Saut, French Guiana), Global Biogeochem. Cycles, 19, GB4007, doi:10.1029/2005GB002457.

Armstrong, R. L., and M. J. Brodzik (2005), Northern Hemisphere EASEGrid weekly snow cover and sea ice extent, version 3, Natl. Snow and Ice Data Cent., Boulder, Colo.

Bousquet, P., D. A. Hauglustaine, P. Peylin, C. Carouge, and P. Ciais (2005), Two decades of $\mathrm{OH}$ variability as inferred by an inversion of atmospheric transport and chemistry of methyl chloroform, Atmos. Chem. Phys., 5, 2635-2656.

Bousquet, P., et al. (2006), The contribution of anthropogenic and natura sources to the variability of atmospheric methane, Nature, 443, 439-443, doi:10.1038/nature05132.

Cao, M., S. Marshall, and K. Gregson (1996), Global carbon exchange and methane emissions from natural wetlands: Application of a processbased model, J. Geophys. Res., 14, 399-414.

Christensen, T. R., A. Ekberg, L. Ström, M. Mastepanov, N. Panikov, M. Öquist, B. H. Svensson, H. Nykänen, P. J. Martikainen, and H. Oskarsson (2003), Factors controlling large scale variations in methane emissions from wetlands, Geophys. Res. Lett., 30(7), 1414, doi:10.1029/ 2002GL016848.

Conrad, R. (1989), Control of methane production in terrestrial ecosystems, in Exchange of Trace Gases Between Terrestrial Ecosystems and the Atmosphere, edited by M. Andreas and D. Schimel, pp. 39-58, John Wiley, Hoboken, N. J.

Dlugokencky, E. J., B. P. Walter, K. A. Masarie, P. M. Lang, and E. S Kasichke (2001), Measurements of an anomalous global methane increase during 1998, Geophys. Res. Lett., 28(3), 499-502, doi:10.1029/ 2000GL012119.

Fung, I., J. John, J. Lerner, E. Matthews, M. Prather, L. P. Steele, and P. J. Fraser (1991), Threedimensional model synthesis of the global methane cycle, J. Geophys. Res., 96, 13,033-13,065, doi:10.1029/91JD01247.

Gurney, K. R., et al. (2002), Towards robust regional estimates of $\mathrm{CO}_{2}$ sources and sinks using atmospheric transport models, Nature, 415 , 626-630, doi:10.1038/415626a.

Hauglustaine, D. A., et al. (2004), Interactive chemistry in the Laboratoire de Meteorologie Dynamique general circulation model: Description and background tropospheric chemistry evaluation, J. Geophys. Res., 109 , D04314, doi:10.1029/2003JD003957.

Hein, R., P. J. Crutzen, and M. Heimann (1997), An inverse modeling approach to investigate the global atmospheric methane cycle, Global Biogeochem. Cycles, 11, 43-76, doi:10.1029/96GB03043.

Houghton, J. T., et al. (Eds.) (2001), Projection of Future Climate Change. Climate Change 2001: The Scientific Contribution Basis, Contribution of Working Group I to the Third Assessment Report of the Intergovernmental Panel on Climate Change, 881 pp., Cambridge Univ. Press, New York.

Hütsch, B. W., J. Augustin, and W. Merbach (2002), Plant rhizodeposition: An important source for carbon turnover in soils, J. Plant Nutr. Soil Sci., 165, 397-408, doi:10.1002/1522-2624(200208)165:4<397:: AID-JPLN397>3.0.CO;2-C.
Kaplan, J. O. (2002), Wetlands at the Last Glacial Maximum: Distribution and methane emissions, Geophys. Res. Lett., 29(6), 1079, doi:10.1029/ 2001 GL013366.

Keller, M. (1990), Biological sources and sinks of methane in tropical habitats and tropical atmospheric chemistry, Ph.D. diss., Coop. Thesis 126, Princeton Univ., Princeton, N. J.

Kelly, C. A., and D. P. Chynoweth (1981), The contributions of temperature and of the input of organic matter in controlling rates of sediment methanogenesis, Limnol. Oceanogr., 26(5), 891-897.

Khyorostyanov, D. V., G. Krinner, P. Ciais, M. Heimann, and S. A. Zimov (2008), Vulnerability of permafrost carbon to global warming. Part 1. Model description and role of heat generated by organic matter decomposition, Tellus, Ser. B, 60, 265-275.

King, J. Y., and W. S. Reeburgh (2002), A pulse-labeling experiment to determine the contribution of recent plant photosynthates to net methane emission in arctic wet sedge tundra, Soil Biol. Biochem., 34(2), 173-180, doi:10.1016/S0038-0717(01)00164-X.

Krinner, G., N. Viovy, N. de Noblet-Ducoudré, J. Ogée, J. Polcher, P. Friedlingstein, P. Ciais, S. Sitch, and I. C. Prentice (2005), A dynamic global vegetation model for studies of the coupled atmosphere-biosphere system, Global Biogeochem. Cycles, 19, GB1015, doi:10.1029/ 2003GB002199.

Liblik, L. K., and T. R. Moore (1997), Methane emissions from wetlands in the zone of discontinuous permafrost: Fort Simpson, Northwest Territories, Canada, Global Biogeochem. Cycles, 11, 485-494, doi:10.1029/ 97GB01935.

Loveland, T. R., B. C. Reed, J. F. Brown, D. O. Ohlen, Z. Zhu, L. Yang, and J. W. Merchant (2000), Development of a global land cover characteristics database and IGBP DISCover from $1 \mathrm{~km}$ AVHRR data, Int. J. Remote Sens., 2l(6/7), 1303-1330.

Matthews, E., and I. Fung (1987), Methane emission from natural wetlands: Global distribution, area, and environmental characteristics of sources, Global Biogeochem. Cycles, 1, 61-86, doi:10.1029/GB001i001p00061.

Matthews, E., I. Fung, and J. Lerner (1991), Methane emission from rice cultivation: Geographic and seasonal distribution of cultivated areas and emissions, Global Biogeochem. Cycles, 5, 3-24, doi:10.1029/ 90GB02311.

Mitsch, W. J., and J. G. Gosselink (2000), Wetlands, 3rd ed., John Wiley, Hoboken, N. J.

Ngo-Duc, T., J. Polcher, and K. Laval (2005), A 53-year forcing data set land surface models, J. Geophys. Res., 110, D06116, doi:10.1029/ 2004JD005434

Olivier, J. G. J., and J. J. M. Berdowski (2001), Global emissions sources and sinks, in The Climate System, edited by J. Berdowski, R. Guichert, and B. Heij, pp. 33-78, A. A. Balkema, Lisse, Netherlands.

Page, S. E., F. Siegert, J. O. Rieley, H.-D. V. Boehm, A. Jaya, and S. Limin (2002), The amount of carbon released from peat and forest fires in Indonesia during 1997, Nature, 420, 61-65, doi:10.1038/nature01131.

Papa, F., C. Prigent, F. Durand, and W. B. Rossow (2006), Wetland dynamics using a suite of satellite observations: A case study of application and evaluation for the Indian Subcontinent, Geophys. Res. Lett., 33 , L08401, doi:10.1029/2006GL025767.

Papa, F., C. Prigent, and W. B. Rossow (2007), Ob' River flood inundations from satellite observations: A relationship with winter snow parameters and river runoff, J. Geophys. Res., 112, D18103, doi:10.1029/ 2007JD008451.

Papa, F., C. Prigent, and W. B. Rossow (2008a), Monitoring flood and discharge variations in the large Siberian rivers from a multi-satellite technique, Surv. Geophys., 29, 297-317, doi:10.1007/s10712-008-9036-0.

Papa, F., A. Güntner, F. Frappart, C. Prigent, and W. B. Rossow (2008b), Variations of surface water extent and water storage in large river basins: A comparison of different global data sources, Geophys. Res. Lett., 35, L11401, doi:10.1029/2008GL033857.

Petrescu, A. M. R., J. van Huissteden, M. Jackowicz-Korczynski, A. Yurova, T. R. Christensen, P. M. Crill, K. Backstrand, and T. C. Maximov (2008), Modelling CH4 emissions from arctic wetlands: Effects of hydrological parameterization, Biogeosciences, 5, 111-121.

Prigent, C., E. Matthews, F. Aires, and W. B. Rossow (2001), Remote sensing of global wetlands dynamics with multiple satellite data sets, Geophys. Res. Lett., 28(24), 4631-4634, doi:10.1029/2001GL013263.

Prigent, C., F. Papa, F. Aires, W. B. Rossow, and E. Matthews (2007) Global inundation dynamics inferred from multiple satellite observations, 1993-2000, J. Geophys. Res., 112, D12107, doi:10.1029/ 2006JD007847.

Shannon, R. D., and J. R. White (1994), A 3-year study of controls on methane emissions from two Michigan peatlands, Biogeochemistry, 27, 35-60, doi:10.1007/BF00002570. 
Shindell, D. T., B. P. Walter, and G. Faluvegi (2004), Impacts of climate change on methane emissions from wetlands, Geophys. Res. Lett., 31, L21202, doi:10.1029/2004GL021009.

Shurpali, N. J., and S. B. Verma (1998), Micrometeorological measurements of methane flux in a Minnesota peatland during two growing seasons, Biogeochemistry, 40, 1-15, doi:10.1023/A:1005875307146.

Uppala, S. M., et al. (2005), The ERA-40 Reanalysis, J. R. Meteorol. Soc., 131, 2961-3012, doi:10.1256/qj.04.176.

Valentine, D. W., E. A. Holland, and D. S. Schimel (1994), Ecosystem and physiological controls over methane production in northern wetlands, J. Geophys. Res., 99(D1), 1563-1571, doi:10.1029/93JD00391.

Van der Werf, G. R., J. T. Randerson, G. J. Collatz, and L. Giglio (2003), Carbon emissions from fires in tropical and subtropical ecosystems, Global Change Biol., 9, 547-562, doi:10.1046/j.1365-2486.2003. 00604.x.

Van der Werf, G. R., et al. (2004), Continental-scale partitioning of fire emissions during the 1997 to 2001 El Niño/La Niña period, Science, 303, 73-76, doi:10.1126/science.1090753.

Walter, B. P., and M. Heimann (2000), A process-based, climate-sensitive model to derive methane emissions from natural wetlands: Application to five wetland sites, sensitivity to model parameters, and climate, Global Biogeochem. Cycles, 14(3), 745-765, doi:10.1029/1999GB001204.

Walter, B. P., M. Heimann, and E. Matthews (2001a), Modelling modern methane emissions from natural wetlands: 1. Model description and results, J. Geophys. Res., 106(D24), 34,189-34,206, doi:10.1029/ 2001JD900165.
Walter, B. P., M. Heimann, and E. Matthews (2001b), Modeling modern methane emissions from natural wetlands: 2. Interannual variations 1982-1993, J. Geophys. Res., 106(D24), 34,207-34,219, doi:10.1029/ 2001JD900164.

Walter, K. M., S. A. Zimov, J. P. Chanton, D. Verbyla, and F. S. Chapin (2006), Methane bubbling from Siberian thaw lakes as a positive feedback to climate warming, Nature, 443, 71-75, doi:10.1038/nature 05040 .

Whiting, G. J., and J. P. Chanton (1993), Primary production control of methane emissions from wetlands, Nature, 364, 794-795, doi:10.1038/ $364794 \mathrm{a} 0$.

Zimov, S. A., Y. V. Voropaev, I. P. Semiletov, S. P. Davidov, S. F. Prosiannikov, F. S. Chapin III, M. C. Chapin, S. Trumbore, and S. Tyler (1997), North Siberian lakes: A methane source fueled by Pleistocene carbon, Science, 277, 800-802, doi:10.1126/science.277.5327.800.

Zobler, L. (1999), Global Soil Types, 1-Degree Grid (Zobler), data set, Oak Ridge Natl. Lab. Distrib. Act. Arch. Cent., Oak Ridge, Tenn., doi:10.3334/ORNLDAAC/418. (Available at http://www.daac.ornl.gov)

P. Bousquet, P. Ciais, N. de Noblet-Ducoudré, and B. Ringeval, Laboratoire des Sciences du Climat et de l'Environnement, Unité mixte CEA, UVSQ, CNRS, Orme des Merisiers, F-91191 Gif-sur-Yvette CEDEX, France. (bruno.ringeval@1sce.ipsl.fr)

F. Papa and W. B. Rossow, NASA Goddard Institute for Space Studies, 2880 Broadway, New York, NY 10025, USA

C. Prigent, Laboratoire d'Etudes du Rayonnement et de la Matière en Astrophysique, Observatoire de Paris, CNRS, F-75014 Paris, France. 